\title{
Infrared Spectroscopy of the Microhydrated Nitrate Ions $\mathrm{NO}_{3}{ }^{-}\left(\mathrm{H}_{2} \mathrm{O}\right)_{1-6}{ }^{\dagger}$
}

\author{
Daniel J. Goebbert, ${ }^{\ddagger}, \mathbb{I}$ Etienne Garand, ${ }^{\S}$ Torsten Wende, ${ }^{\ddagger}$ Risshu Bergmann, ${ }^{\ddagger}$ Gerard Meijer, \\ Knut R. Asmis, ${ }^{*,+}$ and Daniel M. Neumark $*, \S, \perp$ \\ Fritz-Haber-Institut der Max-Planck-Gesellschaft, Faradayweg 4-6, 14195 Berlin, Germany, Department of \\ Chemistry, University of California, Berkeley, California 94720, and Chemical Sciences Division, Lawrence \\ Berkeley National Laboratory, Berkeley, California 94720
}

Received: February 24, 2009; Revised Manuscript Received: April 15, 2009

\begin{abstract}
We present infrared photodissociation spectra of the microhydrated nitrate ions $\mathrm{NO}_{3}{ }^{-}\left(\mathrm{H}_{2} \mathrm{O}\right)_{1-6}$, measured from 600 to $1800 \mathrm{~cm}^{-1}$. The assignment of the spectra is aided by comparison with calculated B3LYP/augcc-pVDZ harmonic frequencies, as well as with higher-level calculations. The IR spectra are dominated by the antisymmetric stretching mode of $\mathrm{NO}_{3}{ }^{-}$, which is doubly degenerate in the bare ion but splits into its two components for most microhydrated ions studied here due to asymmetric solvation of the nitrate core. However, for $\mathrm{NO}_{3}{ }^{-}\left(\mathrm{H}_{2} \mathrm{O}\right)_{3}$, the spectrum reveals no lifting of this degeneracy, indicating an ion with a highly symmetric solvation shell. The first three water molecules bind in a bidentate fashion to the terminal oxygen atoms of the nitrate ion, keeping the planar symmetry. The onset of extensive water-water hydrogen bonding is observed starting with four water molecules and persists in the larger clusters.
\end{abstract}

\section{Introduction}

Nitrate ions, $\mathrm{NO}_{3}{ }^{-}$, are ubiquitous in aqueous-phase chemistry. They are of importance in diverse fields like atmospheric chemistry $^{1}$ and nuclear waste treatment ${ }^{2}$ and as a source of nitrogen for the production of nucleic acids and proteins. ${ }^{3} \mathrm{NO}_{3}{ }^{-}$ is one of the most abundant ionic species in the troposphere and can be formed by rapid acid dissolution of nitric acid in aerosol particles. ${ }^{1}$ The heterogeneous chemistry of aerosols containing such strong acids is of importance for many atmospheric cycles and is primarily governed by the nature of the aerosol surface, which determines if the adsorbed acid molecule dissociates and how the conjugate base anion is hydrated. ${ }^{4}$ It is difficult to obtain such detailed microscopic information directly from bulk measurements. Spectroscopic experiments on isolated anion-water clusters can aid in characterizing the solvent-solute (and solvent-solvent) interaction at the molecular level one water molecule at a time. ${ }^{5,6}$ In this work we investigate the microhydration of $\mathrm{NO}_{3}{ }^{-}$through the infrared spectroscopy of $\mathrm{NO}_{3}{ }^{-}\left(\mathrm{H}_{2} \mathrm{O}\right)_{n}$ clusters, $n=1-6$.

The gas-phase vibrational spectroscopy of $\mathrm{NO}_{3}{ }^{-} \cdot \mathrm{Ar}$ was studied recently by Johnson and co-workers. ${ }^{7} \mathrm{NO}_{3}{ }^{-}$is planar and has three equivalent $\mathrm{N}-\mathrm{O}$ bonds $\left(D_{3 h}\right.$ symmetry). The six vibrational degrees of freedom lead to two bending and two stretching modes, of which two are doubly degenerate. The two bending modes $\left(\mathrm{e}^{\prime}\right.$ and $\left.\mathrm{a}_{2}{ }^{\prime \prime}\right)$ are infrared-active but have low intensity. The symmetric stretching vibration $v_{1}\left(\mathrm{a}_{1}{ }^{\prime}\right)$ is not infrared-active, while the degenerate $v_{3}\left(\mathrm{e}^{\prime}\right)$ antisymmetric stretching vibration is infrared-active. The vibrational predissociation spectrum of $\mathrm{NO}_{3}{ }^{-} \cdot \mathrm{Ar}$ reveals only a single band at $1349 \mathrm{~cm}^{-1}$, which was assigned to the $v_{3}$ mode, suggesting that the nitrate ion retains its three-fold symmetry in the Ar complex.

\footnotetext{
† Part of the "Robert Benny Gerber Festschrift".

* To whom correspondence should be addressed. E-mail: asmis@ fhi-berlin.mpg.de (K.R.A.); DNeumark@berkeley.edu (D.M.N.).

* Fritz-Haber-Institut der Max-Planck-Gesellschaft.

${ }^{\S}$ University of California.

${ }^{\perp}$ Lawrence Berkeley National Laboratory.

"Current address: Department of Chemistry, University of Arizona, Tucson, Arizona 85721-0041.
}

In contrast, this degeneracy does not persist in extended solid and liquid environments. Solvent as well as counterion interactions in aqueous media are sufficiently strong to perturb the electronic structure of $\mathrm{NO}_{3}{ }^{-}$, resulting in a distortion from the $D_{3 h}$ symmetry of the bare anion. These effects lift the degeneracy of vibrational transitions, and render all six vibrational modes both Raman- and IR-active. ${ }^{8-10}$ For finite systems, either aqueous clusters or systems with extended interfaces, molecular dynamics simulations have predicted that nitrate ions, due to their relatively large molecular polarizability, prefer interfacial rather than bulk solvation. ${ }^{11}$ However, vibrational sum-frequency spectroscopy,${ }^{12}$ in combination with more recent calculations, ${ }^{13,14}$ suggests that acid dissociation is thermodynamically disfavored at the water/air interface, so that nitrate ions are bulk-solvated and molecular $\mathrm{HNO}_{3}$ is present at the surface.

Several experiments have been performed on microhydrated $\mathrm{NO}_{3}{ }^{-}$ions, that is, small $\mathrm{NO}_{3}{ }^{-}\left(\mathrm{H}_{2} \mathrm{O}\right)_{n}$ clusters. Lee et al. ${ }^{15}$ measured the sequential hydration energies for $\mathrm{NO}_{3}{ }^{-}\left(\mathrm{H}_{2} \mathrm{O}\right)_{n}$ up to $n=3$, obtaining values of $61(1 \rightarrow 0), 60(2 \rightarrow 1)$, and 58 $\mathrm{kJ} / \mathrm{mol}(3 \rightarrow 2)$. Wang and co-workers ${ }^{16}$ measured the photoelectron spectra for these ions up to $n=6$. Aided by B3LYP/ aug-cc-pVXZ $(\mathrm{X}=\mathrm{D}$ or $\mathrm{T})$ calculations, they concluded that the first three water molecules form the first solvation shell, giving rise to a highly symmetric $\mathrm{NO}_{3}{ }^{-}\left(\mathrm{H}_{2} \mathrm{O}\right)_{3}$ cluster. The next three water molecules form a second solvation shell without direct contact to $\mathrm{NO}_{3}{ }^{-}$. More recently, Pathak et al. ${ }^{17}$ used B3LYP/6-311++ $\mathrm{G}^{* *}$ calculations to investigate the energies for a large number of different isomers up to $\mathrm{NO}_{3}{ }^{-}\left(\mathrm{H}_{2} \mathrm{O}\right)_{8}$. Their findings are distinctly different from previous findings; starting with $n=3$, interwater $\mathrm{H}$-bond formation is competitive with nitrate-water binding, leading to the formation of water rings with nitrate preferring a surface position. With the exception of the smallest ions, they predict different structures compared to those obtained by Wang et al. ${ }^{16}$ Differences from theory for hydrated $\mathrm{NO}_{3}{ }^{-}$, even in the case of small ions, are welldocumented. Several publications suggest either a symmetric $C_{2 v}$ isomer for the monohydrated ion with two equivalent H-bonds ${ }^{17-19}$ or a slightly asymmetric variant of $C_{s}$ symmetry 
with two nonequivalent H-bonds. ${ }^{16,20-23}$ These variations appear to be dependent on the level of theory and basis sets used in the calculation. Also, for larger clusters, for example, $n=3^{16,17,22}$ and $6,{ }^{16,17,20}$ both highly symmetric and asymmetric structures have been proposed as ground-state isomers.

Clearly, many open questions remain regarding the hydration of nitrate ions at the molecular level. Here, we use vibrational spectroscopy of gas-phase clusters to address some of these problems. We measure IR spectra of mass-selected nitrate-water clusters from 600 to $1800 \mathrm{~cm}^{-1}$, the spectral region of characteristic vibrational modes of the ion and the solvent molecules, at low temperature and in the absence of a counterion. This method has proven very useful in recent studies on the microhydration of anions, for example, $\mathrm{SO}_{4}{ }^{2-}$ and $\mathrm{SF}_{6}{ }^{-},{ }^{24-26}$ and on water cluster anions. ${ }^{27,28}$ Similar to $\mathrm{SO}_{4}{ }^{2-}, \mathrm{NO}_{3}{ }^{-}$is of sufficiently high symmetry to support degenerate vibrational levels. This degeneracy can be lifted upon asymmetric solvation, leading to a splitting of vibrational levels and additional bands in the experimental IR spectra, thereby directly probing the hydration shell environment.

\section{Experimental Methods}

Infrared multiple photon photodissociation (IRMPD) experiments ${ }^{29-31}$ were carried out on a previously described ring electrode trap-time-of-flight mass spectrometer, ${ }^{32}$ which was temporarily installed at the Free Electron Laser for Infrared eXperiments (FELIX) user facility ${ }^{33}$ in the FOM Institute, Rijnhuizen (The Netherlands).

Microhydrated $\mathrm{NO}_{3}{ }^{-}$ions were produced by electrospray of a $5 \mathrm{mM}$ solution of ammonium nitrate in a 50:50 mix of water/ acetonitrile using a modified Waters z-spray source. The negative ions were transferred into the high-vacuum system, sampled by a $3 \mathrm{~mm}$ diameter skimmer, and focused into a radio frequency (RF) linear ion guide. Ions of interest were massselected in a quadrupole mass filter, deflected $90^{\circ}$ by an electrostatic quadrupole ion deflector, and focused into the linear ring electrode RF ion trap. The ion trap was filled with He buffer gas and cooled to $10 \mathrm{~K}$ by means of a closed cycle He cryostat. Collisions with the He buffer gas cooled the ions close to the ambient temperature.

IRMPD spectra were obtained by accumulating ions for 195 $\mathrm{ms}$, extracting them into the extraction region of a time-of-flight mass spectrometer, and irradiating them with pulsed radiation from FELIX prior to the application of the high-voltage pulses for the measurement of the TOF mass spectra. FELIX macropulses were produced at $5 \mathrm{~Hz}$ with a pulse length of $5 \mu \mathrm{s}$, a wavelength bandwidth of $0.25 \%$ rms over the range from 600 to $1800 \mathrm{~cm}^{-1}$, and typical pulse energies of up to $50 \mathrm{~mJ}$.

\section{Computational Details}

Electronic structure calculations were performed using the Gaussian 98 and 03 programs. ${ }^{34,35}$ Geometry optimizations were performed for a large number of different isomers of $\mathrm{NO}_{3}{ }^{-}\left(\mathrm{H}_{2} \mathrm{O}\right)_{1-6}$ clusters using density functional theory, employing the B3LYP hybrid exchange-correlation functional ${ }^{36,37}$ and the $6-31+\mathrm{G}^{*}$ basis set. Vibrational frequencies were calculated to ensure that the structures corresponded to local minima. The lowest-energy isomers located from this search were then optimized using the augmented correlation-consistent polarized valence basis set aug-cc-pVDZ. ${ }^{38,39}$ In some instances, small differences in structures between isomers were observed, for instance, a $\mathrm{H}$-atom pointing up or down. In such a case the lowest-energy form was used, but for the purposes of our study, these were not considered distinct isomers, helping to reduce the computational load. Simulated linear absorption spectra were derived from B3LYP/aug-cc-pVDZ scaled harmonic frequencies (scaling factor: 0.97$)^{40}$ and intensities. In order to facilitate comparison with experiment, the resulting stick spectra were convoluted using a Gaussian line shape function with a width of $15 \mathrm{~cm}^{-1}$ (fwhm). All dissociation energies include vibrational zero-point energies and were corrected for the basis set superposition error using the counterpoise correction. ${ }^{41}$

To test the reliability of the results, we performed additional calculations with larger basis sets (aug-cc-pVTZ and aug-ccpVQZ) and other single determinant methods, in particular, MP2 and $\operatorname{CCSD}(\mathrm{T}) .{ }^{42,43}$ In some cases, anharmonic frequencies were determined by numerical differentiation along normal modes using the ANHARMONIC option. For the coupled cluster theory calculations, the T1 diagnostic, ${ }^{44}$ which is a rough measure of the importance of nondynamical correlation effects, was also evaluated. A sufficiently small T1 value $(<\sim 0.02)$ indicates that the $\operatorname{CCSD}(\mathrm{T})$ relative energies should be close to the full CI values.

\section{Results}

IRMPD spectra of $\mathrm{NO}_{3}{ }^{-}\left(\mathrm{H}_{2} \mathrm{O}\right)_{n}$ with $n=1-6$ are shown in Figure 1. The total fragment ion yield, that is, the sum of all individual fragmentation channels, is shown as a function of the photodissociation laser wavelength and reflects the absorption spectrum of the parent ion. This signal is nearly backgroundfree, in contrast to monitoring depletion of the parent ion. Table 1 lists all fragmentation channels observed from photodissociation of the $\mathrm{NO}_{3}{ }^{-}\left(\mathrm{H}_{2} \mathrm{O}\right)_{n}$ series and their relative intensities. Channels involving loss of one or more water molecules are the only fragmentation pathways observed. For the $n=1-4$ ions, water loss down to the formation of bare $\mathrm{NO}_{3}{ }^{-}$is observed. For $n=5$ and 6, fragments corresponding to loss of up to three water molecules are observed. We also find that for $n=6$, the loss of three waters appears to be more efficient than loss of two water molecules. Loss of multiple waters can be enhanced by fragment absorption since they have very similar spectra.

Overview IRMPD spectra $\left(600-1800 \mathrm{~cm}^{-1}\right)$ are shown in panel (a) of Figure 1. Spectra with smaller step sizes and longer acquisition times are shown in panel (b), from 1265 to 1465 $\mathrm{cm}^{-1}$, and panel (c), from 1610 to $1710 \mathrm{~cm}^{-1}$. Most spectra show a pair of peaks centered around $1350 \mathrm{~cm}^{-1}$ (labeled A in Figure 1) and a weaker band around $1660 \mathrm{~cm}^{-1}$ (labeled $\mathrm{B}$ in Figure 1). Features $\mathrm{A}$ and $\mathrm{B}$ correspond to the $\mathrm{NO}_{3}{ }^{-}$antisymmetric stretching mode $v_{3}$ and the water bending modes, respectively. Very weak, if any, signal is observed below 1200 $\mathrm{cm}^{-1}$, where the water librational modes are expected. Feature A shows a pronounced dependence on the number of water molecules in the cluster. A doublet of similarly intense peaks is observed for $n=1,2,5$, and 6 , the center and splitting of which is size-dependent. For $n=3$, only a single intense and narrow band is observed, while $n=4$ is intermediate between the two situations; band A is broad with a hint of a doublet, and an additional, somewhat weaker absorption feature is observed at slightly higher energies $\left(\sim 1390 \mathrm{~cm}^{-1}\right)$. Band B is not observed for $n=1$, increases in relative intensity, and, starting with $n=3$, broadens and blue shifts with increasing cluster size.

Experimental and calculated band positions for bare and microhydrated $\mathrm{NO}_{3}{ }^{-}$ions are summarized in Table 2. Results for several characteristic low-energy isomers, including relative energies corrected for zero-point energies, are listed. In some cases, not all possible structural isomers are listed; we concentrated on finding the global minimum-energy structure, as well 

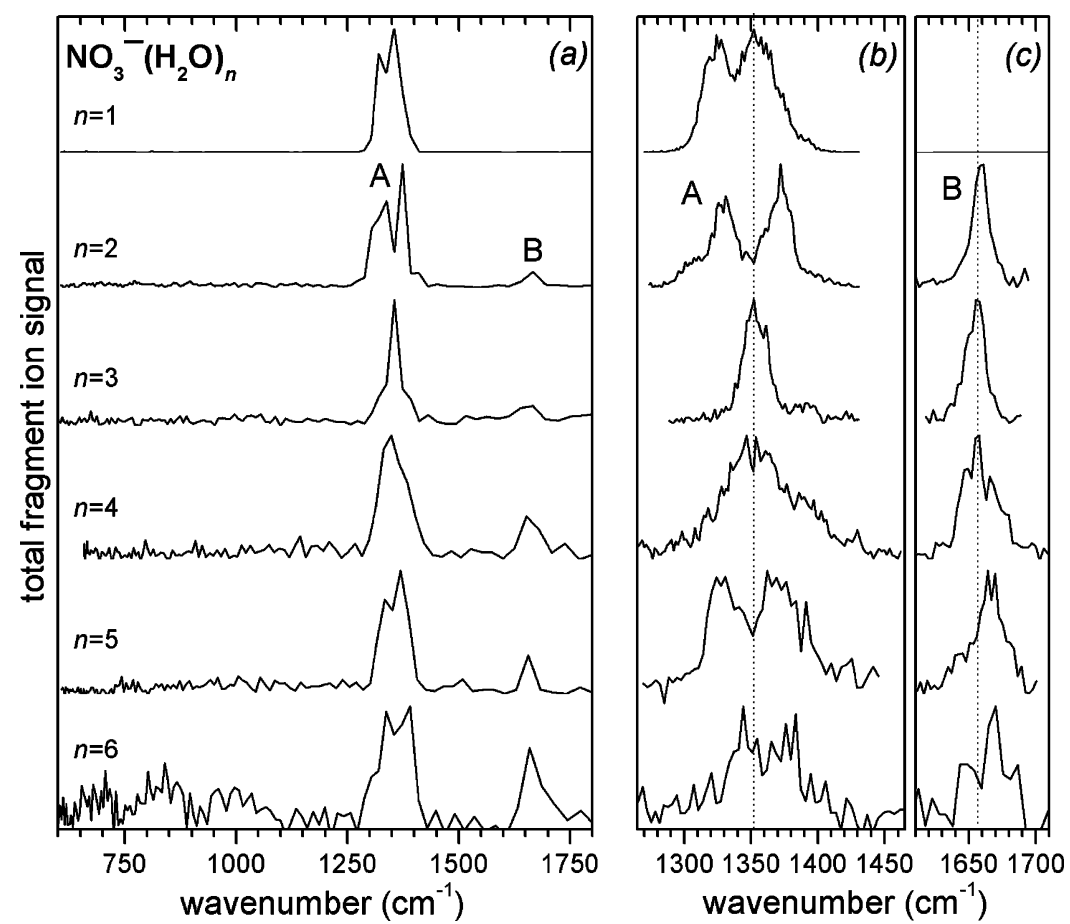

Figure 1. Experimental IRMPD spectra of $\mathrm{NO}_{3}{ }^{-}\left(\mathrm{H}_{2} \mathrm{O}\right)_{n}$ ions with $n=1-6$. The total fragment ion yield is plotted as a function of the photon energy $\left(\mathrm{cm}^{-1}\right)$. (a) Overview scans were measured in the spectral region from 600 to $1800 \mathrm{~cm}^{-1}$. (b,c) Finer scans, covering the range of the $\mathrm{NO}_{3}{ }^{-}$ antisymmetric stretching (band A) and water bending modes (band B) are also shown.

TABLE 1: Observed Photofragmentation Channels and Relative Intensities for Microhydrated $\mathrm{NO}_{3}{ }^{-}$Ions

\begin{tabular}{ccl}
\hline parent ion & fragmentation channels & relative intensities ${ }^{a}$ \\
\hline $\mathrm{NO}_{3}{ }^{-} \cdot \mathrm{H}_{2} \mathrm{O}$ & $-\mathrm{H}_{2} \mathrm{O}$ & 1.00 \\
$\mathrm{NO}_{3}{ }^{-}\left(\mathrm{H}_{2} \mathrm{O}\right)_{2}$ & $-\left(\mathrm{H}_{2} \mathrm{O}\right)_{1,2}$ & $1.00,0.07$ \\
$\mathrm{NO}_{3}{ }^{-}\left(\mathrm{H}_{2} \mathrm{O}\right)_{3}$ & $-\left(\mathrm{H}_{2} \mathrm{O}\right)_{1-3}$ & $1.00,0.31,0.18$ \\
$\mathrm{NO}_{3}{ }^{-}\left(\mathrm{H}_{2} \mathrm{O}\right)_{4}$ & $-\left(\mathrm{H}_{2} \mathrm{O}\right)_{1-4}$ & $1.00,0.23,0.13,0.06$ \\
$\mathrm{NO}_{3}{ }^{-}\left(\mathrm{H}_{2} \mathrm{O}\right)_{5}$ & $-\left(\mathrm{H}_{2} \mathrm{O}\right)_{1-3}$ & $1.00,0.46,0.09$ \\
$\mathrm{NO}_{3}{ }^{-}\left(\mathrm{H}_{2} \mathrm{O}\right)_{6}$ & $-\left(\mathrm{H}_{2} \mathrm{O}\right)_{1-3}$ & $1.00,0.18,0.26$
\end{tabular}

${ }^{a}$ Obtained from the fragmentation pattern measured at the wavelength corresponding to the maximum of the most intense band in the IRMPD spectrum.

as energetically higher-lying isomers that are distinctly different from the global minimum structure, that is, that belong to a different "class" of isomers. The optimized structures and simulated linear absorption spectra are shown together with the experimental IRMPD spectra of the corresponding cluster ion in Figures 2-7. The following sections summarize the theoretical and experimental results for each cluster.

IVA. $\mathbf{N O}_{3}{ }^{-} \cdot \mathbf{H}_{2} \mathbf{O}$. The experimental IRMPD spectrum of $\mathrm{NO}_{3}{ }^{-} \cdot \mathrm{H}_{2} \mathrm{O}$ together with simulated linear absorption spectra of three possible structures is shown in Figure 2. We found two low-lying minimum-energy structures, labeled $\mathbf{1 - \mathbf { I } ^ { \prime }}$ and $\mathbf{1 - I I}$ in Figure 2, which correspond to the doubly and singly $\mathrm{H}$-bonded in-plane isomers. The doubly $\mathrm{H}$-bonded species is 8 $\mathrm{kJ} / \mathrm{mol}$ more stable than the singly H-bonded one. In both cases, addition of the water molecule breaks the three-fold symmetry of $\mathrm{NO}_{3}^{-}$, lifting the degeneracy and inducing a pronounced splitting of the $v_{3}$ band. The simulated spectra of isomers $\mathbf{1 - \mathbf { I } ^ { \prime }}$ and $\mathbf{1 - I I}$ reproduce the position of the $v_{3}$ band but overestimate the extent of the splitting (1-I': $59 \mathrm{~cm}^{-1}$; 1-II: $\left.67 \mathrm{~cm}^{-1}\right)$ compared to that of the experiment $\left(29\right.$ and $33 \mathrm{~cm}^{-1}$ after deconvolution). The spectrum of $\mathbf{1 - \mathbf { I } ^ { \prime }}$ does fit better with regard to the observed intensity ratio (compared to that of $\mathbf{1 - I I}$ ). The calculations also predict two features of lower intensity, corresponding to the water bending $\left(1644 \mathrm{~cm}^{-1}\right)$ and libration modes $\left(735 \mathrm{~cm}^{-1}\right)$, which are not observed experimentally. Possible reasons for the absence of these bands from the experimental IRMPD spectra are discussed later.

As previously reported, ${ }^{16}$ the potential energy surface (PES) of $\mathrm{NO}_{3}{ }^{-} \cdot \mathrm{H}_{2} \mathrm{O}$ exhibits a symmetrically bound $C_{2 v}$ transition state 1-I with identical H-bond lengths (2.05 $\AA$, B3LYP/aug-ccpDVZ), very close in energy to the asymmetrically bound, doubly H-bonded species $\mathbf{1}-\mathbf{I}^{\prime}$, characterized by two different H-bond lengths (1.86 and $2.41 \AA$ ). This first-order transition state lies only $+0.4 \mathrm{~kJ} / \mathrm{mol}$ higher in energy than the $C_{s}$ minimum structure 1-I'. Thus, while the lowest-energy structures are the slightly asymmetric ones, the vibrationally averaged structures are likely to be symmetric. Interestingly, the $C_{2 v}$ structure does represent the global minimum on the B3LYP surface when the smaller and less flexible $6-31+\mathrm{G}^{*}$ basis set is used. With the 6-31++G** basis set used by Pathak et al., ${ }^{17}$ the two structures are nearly isoenergetic (see Table 3).

We also performed MP2 and CCSD(T) calculations, as well as B3LYP calculations using larger basis sets (see Table 3). With the exception of the B3LYP/6-31+G* calculation, the $C_{s}$ structure represents the global minimum independent of the type of single-reference method and the size of basis set used. The value of the T1 diagnostic for the $\operatorname{CCSD}(\mathrm{T})$ calculations is 0.02 , a value on the borderline of suggesting that a multireference determinant approach is required to adequately describe the ground-state geometry of $\mathrm{NO}_{3}{ }^{-} \cdot \mathrm{H}_{2} \mathrm{O}$.

The calculated splitting of the $v_{3}$ band (see Table 3 ) reveals no pronounced dependence on structure $\left(C_{2 v}\right.$ versus $\left.C_{s}\right)$, method, or basis set used. It is nearly twice as large $\left(54-60 \mathrm{~cm}^{-1}\right)$ as the experimentally observed splitting. While the scaled harmonic B3LYP and CCSD(T) frequencies lie within 3\% of the experimental values, the MP2 frequencies are consistently too high by as much as $7 \%$. Including anharmonicity explicitly improves the agreement only slightly for the B3LYP/aug-ccpVDZ calculation but not for MP2/aug-cc-pVDZ. The simulated spectra of $\mathbf{1 - I}$ and $\mathbf{1 - \mathbf { I } ^ { \prime }}$ are very similar in the region discussed 
TABLE 2: Experimental and Calculated IR Absorption Frequencies $\left(\mathrm{cm}^{-1}\right)$ of the Nitrate Antisymmetric Stretching (band A) and Water Bending Modes (band B) for Bare and Microhydrated $\mathrm{NO}_{3}{ }^{-}$Ions along with Scaled ${ }^{a}$ Harmonic B3LYP/aug-cc-pVDZ Frequencies and Relative Energies (in $\mathrm{kJ} / \mathrm{mol}$ ) for Several Energetically Low-Lying Structures

\begin{tabular}{|c|c|c|c|c|c|}
\hline ion & structure & symmetry & $\begin{array}{c}\text { energy }^{b} \\
(\mathrm{~kJ} / \mathrm{mol})\end{array}$ & $\begin{array}{c}\text { band A } \\
\left(\mathrm{cm}^{-1}\right)\end{array}$ & $\begin{array}{c}\text { band } \mathrm{B}^{c} \\
\left(\mathrm{~cm}^{-1}\right)\end{array}$ \\
\hline \multirow[t]{2}{*}{$\mathrm{NO}_{3}^{-}$} & $\exp$ & & & $1349^{c}$ & \\
\hline & & $D_{3 h}$ & 0.0 & 1340 & \\
\hline \multirow[t]{4}{*}{$\mathrm{NO}_{3}{ }^{-} \cdot \mathrm{H}_{2} \mathrm{O}$} & $\exp$ & & & 1324,1353 & \\
\hline & $1-\mathrm{I}^{\prime}$ & $C_{s}$ & $0.0(0.0)$ & 1324,1383 & 1654 \\
\hline & $1-\mathbf{I}^{e}$ & $C_{2 v}$ & $(0.4)$ & 1325,1379 & 1648 \\
\hline & 1-II & $C_{s}$ & $7.7(9.3)$ & 1325,1393 & 1633 \\
\hline \multirow[t]{5}{*}{$\mathrm{NO}_{3}^{-}\left(\mathrm{H}_{2} \mathrm{O}\right)_{2}$} & $\exp$ & & & 1329,1372 & 1661 \\
\hline & $2-I^{\prime}$ & $C_{s}$ & $0.0(0.0)$ & 1359 & 1640 \\
\hline & $2-\mathrm{I}^{e}$ & $C_{2 v}$ & $(1.2)$ & 1330,1380 & 1633 \\
\hline & 2-II & $C_{1}$ & $5.3(3.3)$ & 1319,1407 & 1649 \\
\hline & 2-III & $C_{s}$ & $6.7(8.0)$ & 1349,1374 & 1648 \\
\hline \multirow[t]{7}{*}{$\mathrm{NO}_{3}^{-}\left(\mathrm{H}_{2} \mathrm{O}\right)_{3}$} & $\exp$ & & & 1352 & 1655 \\
\hline & 3-I' & $C_{3 v}$ & $0.0(0.0)$ & 1363 & 1635 \\
\hline & 3-I ${ }^{e}$ & $D_{3 h}$ & $(2.3)$ & 1355 & 1625 \\
\hline & 3-II & $C_{1}$ & $5.8(-1.4)$ & 1306,1422 & 1623 \\
\hline & 3-III & $C_{1}$ & $6.3(3.0)$ & 1314,1416 & 1608 \\
\hline & 3-IV & $C_{3}$ & $10.5(2.6)$ & 1352 & 1647 \\
\hline & $3-\mathrm{V}$ & $C_{3 h}$ & $17.3(20.7)$ & 1372 & 1626 \\
\hline \multirow{5}{*}{$\mathrm{NO}_{3}^{-}\left(\mathrm{H}_{2} \mathrm{O}\right)_{4}$} & $\exp$ & & & 1345,1357 & 1657 \\
\hline & 4-I & $D_{3 h}$ & $0.0(0.0)$ & 1342,1372 & 1643 \\
\hline & 4-II & $C_{3 v}$ & $2.1(14.2)$ & 1332,1397 & 1629 \\
\hline & 4-III & $C_{1}$ & $3.5(9.2)$ & 1337,1392 & 1633 \\
\hline & 4-IV & $C_{1}$ & $7.0(15.3)$ & 1305,1444 & 1633 \\
\hline \multirow[t]{5}{*}{$\mathrm{NO}_{3}^{-}\left(\mathrm{H}_{2} \mathrm{O}\right)_{5}$} & $\exp$ & & & 1327,1368 & 1667 \\
\hline & $5-I$ & $C_{1}$ & $0.0(0.0)$ & 1327,1391 & 1643 \\
\hline & 5-II & $C_{1}$ & $8.3(10.8)$ & 1288,1435 & 1643 \\
\hline & 5-III & $C_{1}$ & $11.1(13.5)$ & 1318,1408 & 1633 \\
\hline & 5-IV & $C_{1}$ & $11.2(18.1)$ & 1331,1397 & 1625 \\
\hline \multirow[t]{5}{*}{$\mathrm{NO}_{3}^{-}\left(\mathrm{H}_{2} \mathrm{O}\right)_{6}$} & $\exp$ & & & 1345,1374 & 1670 \\
\hline & 6-I & $C_{1}$ & $0.0(0.0)$ & 1330,1399 & 1631 \\
\hline & 6-II & $C_{1}$ & $4.1(5.0)$ & 1325,1395 & 1644 \\
\hline & 6-III & $C_{1}$ & $7.0(9.6)$ & 1325,1395 & 1641 \\
\hline & 6-IV & $C_{1}$ & $18.7(20.0)$ & 1316,1410 & 1637 \\
\hline
\end{tabular}

${ }^{a}$ Scaling factor: 0.97. ${ }^{b}$ With and without (in parentheses) zero-point energy. ${ }^{c}$ Value from ref $7 .{ }^{d}$ Only the band maximum of band $\mathrm{B}$ in the simulated spectra is listed. ${ }^{e}$ First $(n=1)$, second $(n$ $=2)$, and third $(n=3)$ order transition state, respectively.

here (see Figure 2 and Table 3), and do not allow one to decide if the water molecule is bound symmetrically or asymmetrically to the ionic core. However, they do differ significantly in the $\mathrm{O}-\mathrm{H}$ stretching region, and experiments in this spectral region could be used to distinguish between the $C_{2 v}$ and $C_{s}$ structures. Finally, the B3LYP, MP2, and CCSD(T)/aug-cc-pVDZ dissociation energies are 55, 64, and $66 \mathrm{~kJ} / \mathrm{mol}$, respectively, in reasonable agreement with the experimental value $(61 \mathrm{~kJ} / \mathrm{mol}) .{ }^{15}$

IVB. $\mathbf{N O}_{3}^{-}\left(\mathbf{H}_{2} \mathrm{O}\right)_{2}$. The experimental IRMPD spectrum of $\mathrm{NO}_{3}{ }^{-}\left(\mathrm{H}_{2} \mathrm{O}\right)_{2}$ is shown in Figure 3. Addition of the second water molecule leads to an increase of the splitting in the $v_{3}$ band to $43 \mathrm{~cm}^{-1}$. A weaker, symmetrically shaped band, assigned to the water bending modes, is observed at $1661 \mathrm{~cm}^{-1}$. The lowestenergy structure found (2-I'; see Figure 3 ) is of $C_{2 v}$ symmetry and consists of two waters, each bound to the nitrate core by a shorter $(1.88 \AA)$ and a longer H-bond $(2.54 \AA)$. In analogy to structure 1-I for $n=1$, a transition state (2-I, $C_{2 v}$ symmetry) in which the four H-bond lengths (2.07 and $2.13 \AA$ ) are more similar, is found only slightly higher in energy. Due to the presence of two water molecules, this transition state is of second order and connects several shallow minimum structures $\left(\mathbf{2}-\mathbf{I}^{\prime}\right.$ to $2-\mathbf{I}^{\prime \prime \prime}$ ), which all lie close in energy (see Table 4) and differ in the positions of the shorter and the longer H-bonds.

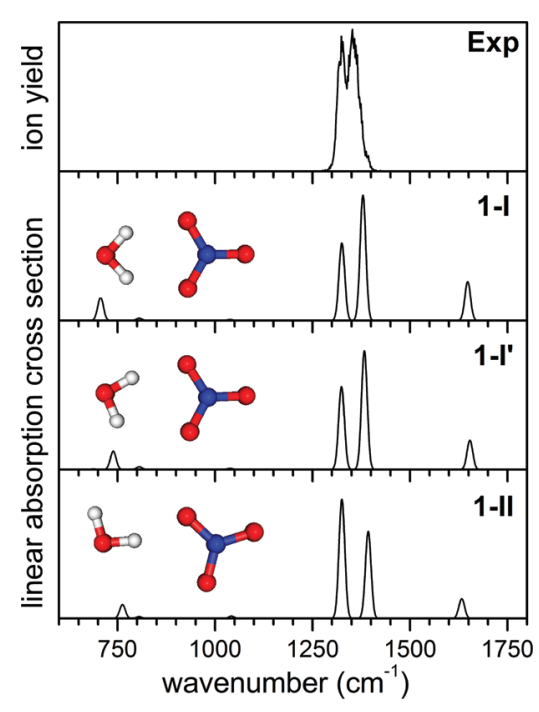

Figure 2. Experimental IRMPD (top) and simulated linear absorption spectra of $\mathrm{NO}_{3}{ }^{-} \cdot \mathrm{H}_{2} \mathrm{O}$. Simulated spectra, derived from B3LYP2/augcc-pVDZ scaled harmonic frequencies and intensities and convoluted using a Gaussian line shape function with a fwhm of $15 \mathrm{~cm}^{-1}$, and structures are shown for three isomers (see text).

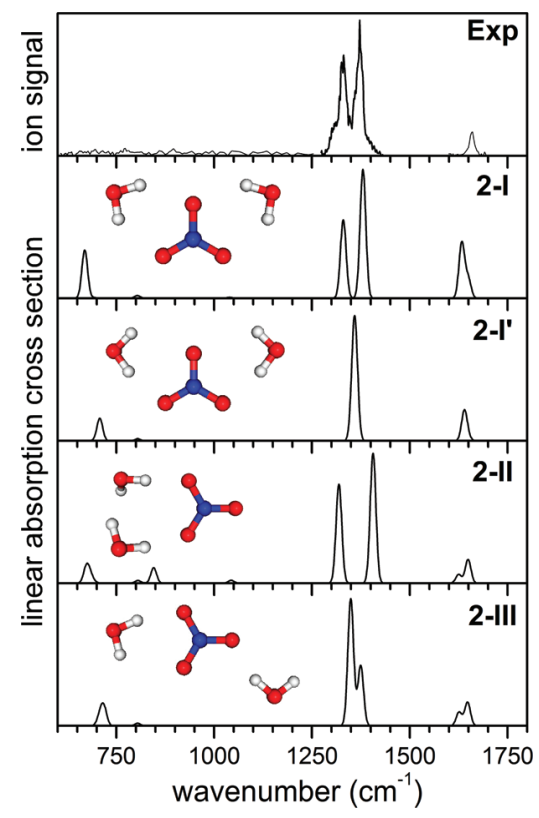

Figure 3. Experimental IRMPD (top) and simulated linear absorption spectra of $\mathrm{NO}_{3}{ }^{-}\left(\mathrm{H}_{2} \mathrm{O}\right)_{2}$. Simulated spectra, derived from B3LYP2/augcc-pVDZ scaled harmonic frequencies and intensities and convoluted using a Gaussian line shape function with a fwhm of $15 \mathrm{~cm}^{-1}$, and structures are shown for four isomers (see text).

The B3LYP calculations predict a characteristic $v_{3}$ band splitting for each one of these structures (Table 4), ranging from $3 \mathrm{~cm}^{-1}$ in $\mathbf{2}-\mathbf{I}^{\prime}$ to $77 \mathrm{~cm}^{-1}$ in $\mathbf{2}-\mathbf{I}^{\prime \prime \prime}$. The agreement between the experimental value $\left(43 \mathrm{~cm}^{-1}\right)$ and the value of the minimumenergy structure $\mathbf{2}-\mathbf{I}^{\prime}\left(3 \mathrm{~cm}^{-1}\right)$ is clearly poor, and much better agreement is found for the transition state $2-\mathbf{I}\left(54 \mathrm{~cm}^{-1}\right)$, suggesting that either the minimum-energy structures are real, but the barriers to interconversion are small and an averaged "symmetrically" H-bonded structure is probed by our experiment, or that structures $\mathbf{2}-\mathbf{I}^{\prime}$ to $\mathbf{2}-\mathbf{I}^{\prime \prime \prime}$ are artifacts of the singledeterminant-based electronic structure calculations. The next higher energy isomer, $\mathbf{2}$-II $(+5 \mathrm{~kJ} / \mathrm{mol})$, consists of two water molecules bound to each other with each forming a single $\mathrm{H}$-bond to the nitrate core, followed by 2 -III $(+7 \mathrm{~kJ} / \mathrm{mol})$, which 
TABLE 3: Experimental and Calculated IR Absorption Frequencies $\left(\mathrm{cm}^{-1}\right)$ of the $v_{3}$ Mode for $\mathrm{NO}_{3}{ }^{-} \cdot \mathrm{H}_{2} \mathrm{O}$ along with Scaled Harmonic $^{a}$ and Unscaled Anharmonic (in parentheses) Frequencies, As Well As Relative Energies (in kJ/mol) for The $C_{2 v}(1-\mathrm{I})$ and $C_{s}\left(1-I^{\prime}\right)$ Structures

\begin{tabular}{|c|c|c|c|c|c|c|}
\hline method & basis set & structure $^{b}$ & $\Delta E$ & $v_{3}^{\prime}$ & $v_{3}^{\prime \prime}$ & $\Delta v_{3}$ \\
\hline EXP & & & & 1324 & 1353 & 29 \\
\hline \multirow[t]{6}{*}{ B3LYP } & $6-31+\mathrm{G}^{* *}$ & $C_{2 v} / \mathrm{MIN}$ & 0.0 & $1326\left(1346^{c}\right)$ & $1384(1407)$ & $58(61)$ \\
\hline & $6-311++\mathrm{G}^{* *}$ & $C_{2 v} / \mathrm{TS}$ & 0.01 & 1325 & 1383 & 58 \\
\hline & aug-cc-pVDZ & $C_{2 v} / \mathrm{TS}$ & 0.4 & 1325 & 1379 & 54 \\
\hline & & $C_{s} / \mathrm{MIN}$ & 0.0 & $1324(1330)$ & $1383(1381)$ & $58(51)$ \\
\hline & aug-cc-pVTZ & $C_{2 v} / \mathrm{TS}$ & 0.3 & 1300 & 1337 & 56 \\
\hline & & $C_{S} / \mathrm{MIN}$ & 0.0 & 1309 & 1369 & 59 \\
\hline \multirow[t]{4}{*}{ MP-2 } & aug-cc-pVDZ & $C_{2 v} / \mathrm{TS}$ & 0.3 & 1401 & 1455 & 54 \\
\hline & & $C_{s} / \mathrm{MIN}$ & 0.0 & $1400(1430)$ & $1459(1491)$ & $59(61)$ \\
\hline & aug-cc-pVTZ & $C_{2 v} / \mathrm{TS}$ & 0.2 & 1378 & 1439 & 62 \\
\hline & & $C_{s} / \mathrm{MIN}$ & 0.0 & 1380 & 1434 & 54 \\
\hline \multirow[t]{2}{*}{$\operatorname{CCSD}(\mathrm{T})$} & aug-cc-pVDZ & $C_{2 v} / \mathrm{TS}^{d}$ & 0.3 & 1320 & 1377 & 57 \\
\hline & & $C_{s} / \mathrm{MIN}^{d}$ & 0.0 & 1319 & 1379 & 60 \\
\hline
\end{tabular}

${ }^{a}$ Scaling factors from ref 45; B3LYP/6-31+G**, 6-31++G** (0.964), B3LYP/aug-cc-pVxZ (0.97), MP2/aug-cc-pVDZ (0.959), MP2/ aug-cc-pVTZ(0.953), CCSD(T)/aug-cc-pVDZ (0.982). ${ }^{b}$ Symmetry and type (MIN = minimum, TS $=$ transition state). ${ }^{c}$ Anharmonic frequency in parentheses. ${ }^{d} \mathrm{~T} 1$ diagnostic: 0.020 .

TABLE 4: B3LYP and MP2 Relative Energies (in $\mathrm{kJ} / \mathrm{mol})$ without $(\Delta E)$ and with $\left(\Delta E_{0}\right)$ Zero-Point Energies of Several Optimized, Low-Energy Structures of $\mathrm{NO}_{3}{ }^{-}\left(\mathrm{H}_{2} \mathrm{O}\right)_{2}$ along with the Splitting of the $\mathrm{NO}_{3}{ }^{-}$Antisymmetric Stretching Frequencies $\left(\Delta v_{3}\right.$, in $\left.\mathrm{cm}^{-1}\right)$

\begin{tabular}{|c|c|c|c|c|c|c|c|c|c|}
\hline \multirow[b]{2}{*}{ structure } & \multicolumn{3}{|c|}{ B3LYP/aug-cc-pVDZ } & \multicolumn{3}{|c|}{ B3LYP/aug-cc-pVTZ } & \multicolumn{3}{|c|}{ MP2/aug-cc-pVDZ } \\
\hline & $\Delta E$ & $\Delta E_{0}$ & $\Delta v_{3}$ & $\Delta E$ & $\Delta E_{0}$ & $\Delta v_{3}$ & $\Delta E$ & $\Delta E_{0}$ & $\Delta v_{3}$ \\
\hline $2-\mathbf{I}^{a}$ & 1.2 & & 50 & 1.0 & & 50 & 0.8 & & 54 \\
\hline $2-I^{\prime \prime}$ & 0.0 & 0.2 & 54 & 0.2 & 0.0 & 54 & 0.0 & -0.1 & 57 \\
\hline $2-I^{\prime \prime \prime}$ & 0.7 & 0.7 & 77 & 0.6 & 0.4 & 79 & 0.4 & 0.2 & 88 \\
\hline 2-II & 3.3 & 5.3 & 87 & 2.6 & 4.7 & 89 & 2.9 & 4.9 & 97 \\
\hline 2-III & 8.0 & 6.7 & 25 & 7.6 & 6.4 & 27 & 9.8 & 8.4 & 22 \\
\hline
\end{tabular}

${ }^{a}$ Second-order transition state.

is similar to $\mathbf{2}-\mathbf{I}^{\prime}$ except that one of the waters is singly H-bonded to the nitrate anion. The spectra calculated for 2-II and 2-III show poorer agreement with the experimental spectrum than 2-I.

IVC. $\mathrm{NO}_{3}{ }^{-}\left(\mathrm{H}_{2} \mathrm{O}\right)_{3}$. The experimental IRMPD spectrum of $\mathrm{NO}_{3}{ }^{-}\left(\mathrm{H}_{2} \mathrm{O}\right)_{3}$ (see Figure 4) shows a single, narrow peak at 1359 $\mathrm{cm}^{-1}$ and a less intense band at $1658 \mathrm{~cm}^{-1}$. In contrast to the IRMPD spectra of the $n=1$ and 2 species, the $v_{3}$ band in the $n=3$ spectrum exhibits no splitting, suggesting a highly symmetric hydration shell which supports degenerate energy levels in the nitrate ion. This is confirmed by the B3LYP calculations, which find the planar isomer $\mathbf{3}-\mathbf{I}^{\prime}$ of $C_{3 h}$ symmetry as the global minimum on the PES. In $\mathbf{3}-\mathbf{I}^{\prime}$, the three water molecules each form a shorter and a longer $\mathrm{H}$-bond with $\mathrm{NO}_{3}{ }^{-}$. Similar to the situation for $n=1$, there exists a structure, labeled 3-I in Figure 4, in which all three water molecules are symmetrically bound with equal H-bond distances (2.15 ̊). 3-I corresponds to a third-order transition state of $D_{3 h}$ symmetry and, similar to $n=1$ and 2, likely resembles the vibrationally averaged structure that is probed in the experiment. Both $3-\mathbf{I}^{\prime}$ and 3-I have very similar spectra, and unlike for $\mathbf{2}-\mathbf{I}$, it is not possible to rule out one structure. B3LYP calculations using the larger aug-cc-pVTZ basis set as well as MP2 calculations (see Table 5) confirm $\mathbf{3}-\mathbf{I}^{\prime}$ as the lowest-energy structure.

Isomers that contain water-water H-bonds (labeled 3-II to 3-IV in Figure 4) are calculated at similar energies (see Table 5). However, when zero-point energy is considered, the DFT calculations disfavor these isomers by $6 \mathrm{~kJ} / \mathrm{mol}$ or more relative to $\mathbf{3}-\mathbf{I}^{\prime}$. This effect is also reproduced by the MP2 calculations, but the energy differences are smaller. Two of these isomers contain a three-membered water ring, which binds either from

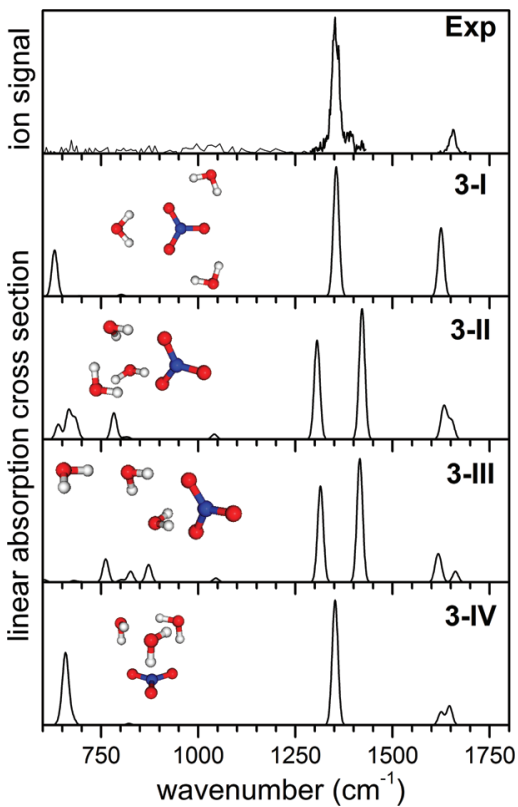

Figure 4. Experimental IRMPD (top) and simulated linear absorption spectra of $\mathrm{NO}_{3}^{-}\left(\mathrm{H}_{2} \mathrm{O}\right)_{3}$. Simulated spectra, derived from B3LYP2/augcc-pVDZ scaled harmonic frequencies and intensities and convoluted using a Gaussian line shape function with a fwhm of $15 \mathrm{~cm}^{-1}$, and structures are shown for four isomers (see text). 
TABLE 5: B3LYP and MP2 Relative Energies (in $\mathrm{kJ} / \mathrm{mol})$ without $(\Delta E)$ and with $\left(\Delta E_{0}\right)$ Zero-Point Energies of Several Optimized, Low-Energy Structures of $\mathrm{NO}_{3}{ }^{-}\left(\mathrm{H}_{2} \mathrm{O}\right)_{3}$ along with the Splitting of the $\mathrm{NO}_{3}{ }^{-}$Antisymmetric Stretching Frequencies $\left(\Delta v_{3}\right.$, in $\left.\mathbf{c m}^{-1}\right)$

\begin{tabular}{|c|c|c|c|c|c|c|c|c|c|}
\hline \multirow[b]{2}{*}{ structure } & \multicolumn{3}{|c|}{ B3LYP/aug-cc-pVDZ } & \multicolumn{3}{|c|}{ B3LYP/aug-cc-pVTZ } & \multicolumn{3}{|c|}{ MP2/aug-cc-pVDZ } \\
\hline & $\Delta E$ & $\Delta E_{0}$ & $\Delta v_{3}$ & $\Delta E$ & $\Delta E_{0}$ & $\Delta v_{3}$ & $\Delta E$ & $\Delta E_{0}$ & $\Delta v_{3}$ \\
\hline 3-I ${ }^{a}$ & 2.3 & & 0 & 1.8 & & 0 & 1.4 & & 0 \\
\hline $3-I^{\prime}$ & 0.0 & 0.0 & 0 & 0.0 & 0.0 & 0 & 0.0 & 0.0 & 0 \\
\hline 3-II & -1.4 & 5.8 & 116 & -2.0 & 5.9 & 117 & -4.6 & 3.1 & 132 \\
\hline 3-III & 3.0 & 6.3 & 101 & 2.3 & 6.1 & 102 & -0.8 & 4.7 & 136 \\
\hline 3-IV & 2.6 & 10.5 & 0 & 1.6 & 10.1 & 0 & -6.5 & 2.0 & 0 \\
\hline $3-V$ & 20.7 & 17.3 & 0 & 19.5 & 16.6 & 0 & 25.8 & 22.2 & 0 \\
\hline
\end{tabular}

${ }^{a}$ Third-order transition state.

the side (3-II) or from the top (3-IV), leading to $C_{1}$ and $C_{3}$ structures, respectively. 3-II was suggested by Pathak et al. ${ }^{17}$ as the lowest-energy structure. Due to its pronounced asymmetry, it is predicted to have a characteristically large $v_{3}$ splitting of $102 \mathrm{~cm}^{-1}$, which immediately disqualifies it as a possible candidate for the explanation of our measured spectrum for $n$ $=3$. Isomer $\mathbf{3}$-III represents the first isomer that contains a water molecule in the second solvation shell, that is, which does not directly bind to $\mathrm{NO}_{3}{ }^{-}$. This structure also leads to two separate peaks in the water bending region, which is not observed. Isomer $\mathbf{3 - V}$ corresponds to the three-fold singly H-bonded version of $\mathbf{3}-\mathbf{I}^{\prime}$. Note that structures $\mathbf{3}-\mathbf{I V}$ and $\mathbf{3}-\mathbf{V}$ are of sufficiently high symmetry to support degenerate vibrational levels, and consequently, their simulated IR spectra are characterized by a single peak for the $v_{3}$ mode, as is observed in our experimental spectrum. However, our calculations (see Table 5) convincingly show that these isomers lie too high in energy to be considered as possible ground-state structures for $n=3$.

IVD. $\mathrm{NO}_{3}{ }^{-}\left(\mathrm{H}_{2} \mathrm{O}\right)_{4}$. The experimental IRMPD of $\mathrm{NO}_{3}{ }^{-}\left(\mathrm{H}_{2} \mathrm{O}\right)_{4}$, simulated linear absorption spectra, and structures of four isomers are shown in Figure 5. The experimental spectrum is different from the previously discussed spectra in that band A is asymmetric and much broader (fwhm of $\sim 70 \mathrm{~cm}^{-1}$ ). There is a hint of two closely spaced maxima with similar intensity, at approximately 1345 and $1357 \mathrm{~cm}^{-1}$. A shoulder with half of the intensity of the main peak is observed at around $1395 \mathrm{~cm}^{-1}$. Band $\mathrm{B}\left(1657 \mathrm{~cm}^{-1}\right)$ has grown in intensity and width relative to the spectra of the smaller clusters.

We find 4-I to be the global minimum-energy structure, which consists of a four-membered water ring sitting on top of the plane spanned by the nitrate ion and in which each water molecule binds to the nitrate ion with a single hydrogen bond. This structure is $2.1 \mathrm{~kJ} / \mathrm{mol}$ lower in energy than the next isomer found (4-II), which corresponds to the " $3+1$ " structure obtained by Wang and co-workers. ${ }^{16}$ In 4-II, the nitrate anion is solvated by three waters in a manner analogous to $3-\mathbf{I}$, with the fourth water molecule occupying the second hydration shell and bound to one of the first hydration shell waters by a single $\mathrm{H}$-bond. The next isomers higher in energy are 4-III $(+3.5 \mathrm{~kJ} /$ $\mathrm{mol})$ and 4-IV $(+7.0 \mathrm{~kJ} / \mathrm{mol})$. 4-III involves a network of three water molecules $\mathrm{H}$-bonded to one another in a ring similar to 3-II, while the fourth water is bound in a bidentate fashion to the nitrate separately. Structure 4-IV consists of two waters singly $\mathrm{H}$-bonded to one of the nitrate $\mathrm{O}$-atoms and a water forming a bridge between the core bound waters, while the fourth water is singly $\mathrm{H}$-bonded to the bridge water.

The spectrum for isomer 4-I, the lowest-energy isomer found, shows the best agreement with experiment in the region of bands $\mathrm{A}$ and $\mathrm{B}$. The calculated splitting of band A, which is barely resolved in the experimental spectrum $\left(12 \mathrm{~cm}^{-1}\right)$, is smallest

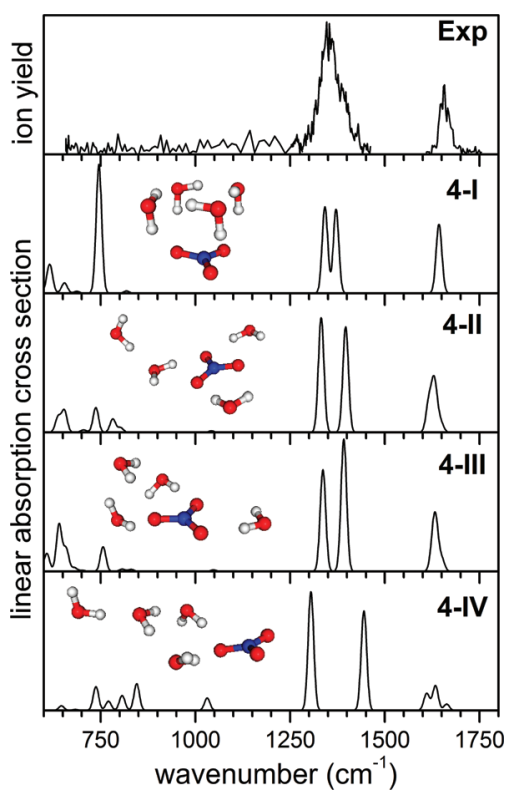

Figure 5. Experimental IRMPD (top) and simulated linear absorption spectra of $\mathrm{NO}_{3}{ }^{-}\left(\mathrm{H}_{2} \mathrm{O}\right)_{4}$. Simulated spectra, derived from B3LYP2/augcc-pVDZ scaled harmonic frequencies and intensities and convoluted using a Gaussian line shape function with a fwhm of $15 \mathrm{~cm}^{-1}$, and structures are shown for four isomers (see text).

for isomer 4-I $\left(30 \mathrm{~cm}^{-1}\right)$ compared to that for the other three isomers $\left(>50 \mathrm{~cm}^{-1}\right)$. The additional structure observed in the experimental spectrum of $n=4$ may be rationalized by assuming the presence of a second isomer (4-II) with a relative abundance of roughly $40 \%$ with respect to the first isomer. The shoulder observed at $\sim 1390 \mathrm{~cm}^{-1}$ agrees well with the predicted absorption band at $1388 \mathrm{~cm}^{-1}$ of $\mathbf{4}$-II, and its water bending modes are shifted to the red compared to those in 4-I, which could explain the observed broadening of band B compared to that for $n=3$. In contrast to the energetically higher-lying isomers, $\mathbf{4 - I}$ is characterized by a very intense peak at $744 \mathrm{~cm}^{-1}$, which is due to a collective wagging motion of the four water molecules comprising the four-membered ring. This peak is not observed in the experimental spectra, possibly due to a conformation change during the IRMPD mechanism (see Discussion and Conclusions).

IVE. $\mathrm{NO}_{3}{ }^{-}\left(\mathrm{H}_{2} \mathrm{O}\right)_{5}$. The experimental IRMPD spectrum of $\mathrm{NO}_{3}{ }^{-}\left(\mathrm{H}_{2} \mathrm{O}\right)_{5}$ (see Figure 6) reveals three peaks at 1327, 1368, and $1667 \mathrm{~cm}^{-1}$. Compared to that for $n=4$, the splitting of band $\mathrm{A}$ is well-resolved $\left(41 \mathrm{~cm}^{-1}\right)$, suggesting a significantly less symmetric hydration shell. Band B is blue shifted by +10 $\mathrm{cm}^{-1}$ with respect to $n=4$. The lowest-energy structures (see Figure 6) for $n=5$ and 4 are similar; 5-I and 4-I both include a four-membered water ring bound to the nitrate ion. For $n=$ 5 , the additional water molecule is doubly $\mathrm{H}$-bonded to the core, 


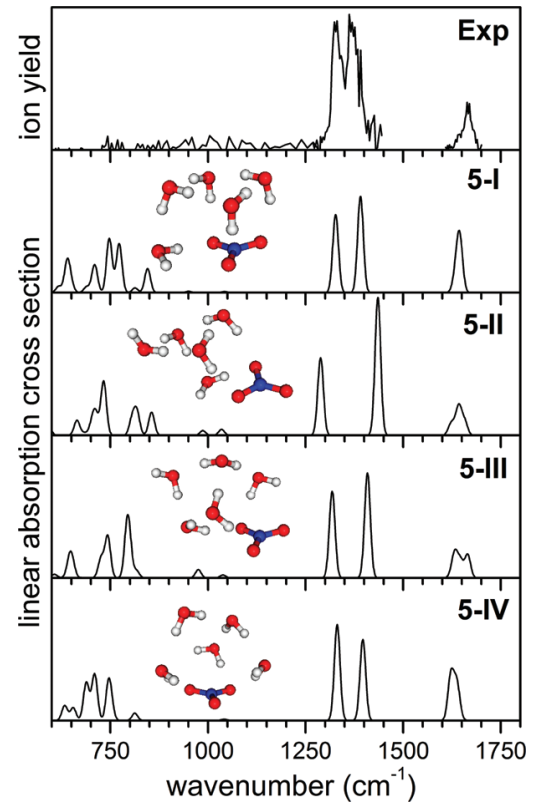

Figure 6. Experimental IRMPD (top) and simulated linear absorption spectra of $\mathrm{NO}_{3}{ }^{-}\left(\mathrm{H}_{2} \mathrm{O}\right)_{5}$. Simulated spectra, derived from B3LYP2/augcc-pVDZ scaled harmonic frequencies and intensities and convoluted using a Gaussian line shape function with a fwhm of $15 \mathrm{~cm}^{-1}$, and structures are shown for four isomers (see text).

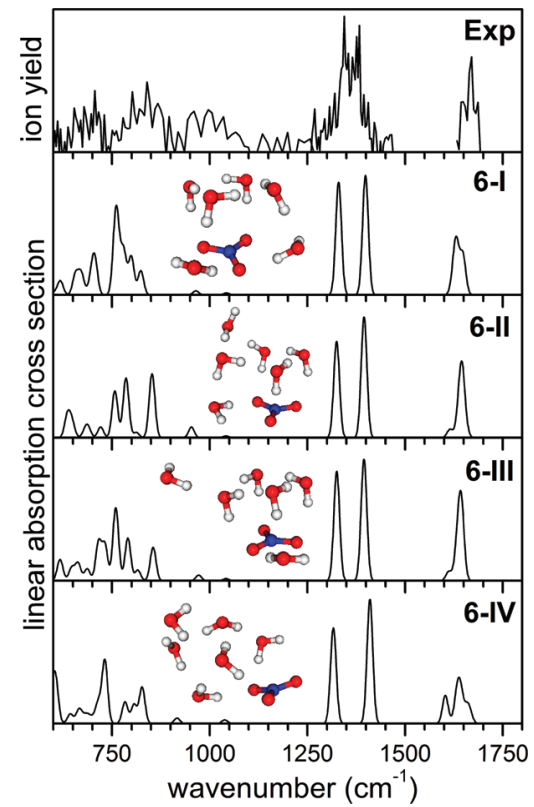

Figure 7. Experimental IRMPD (top) and simulated linear absorption spectra of $\mathrm{NO}_{3}{ }^{-}\left(\mathrm{H}_{2} \mathrm{O}\right)_{6}$. Simulated spectra, derived from B3LYP2/augcc-pVDZ scaled harmonic frequencies and intensities and convoluted using a Gaussian line shape function with a fwhm of $15 \mathrm{~cm}^{-1}$, and structures are shown for four isomers (see text).

lying in the plane of the nitrate anion and accepting a H-bond from one of the out-of-plane waters. All other isomers lie considerably higher in energy and contain two water molecules that do not directly bind to the nitrate ion. Isomer 5-II $(+8$ $\mathrm{kJ} / \mathrm{mol}$ ) is similar to $\mathbf{3}-\mathbf{I I}$, with a ring of three waters connecting sideways to $\mathrm{NO}_{3}{ }^{-}$. Isomer $\mathbf{5}$-III $(+11.1 \mathrm{~kJ} / \mathrm{mol})$ is similar to 5-II but contains a water molecule that forms two H-bonds with $\mathrm{NO}_{3}{ }^{-}$. Isomer $5-\mathbf{I V}(+11.2 \mathrm{~kJ} / \mathrm{mol})$ has a unique structure. It is related to isomer 3-I, in which three water molecules are bound to $\mathrm{NO}_{3}{ }^{-}$in a bidentate fashion. However, the two remaining water molecules form bridging $\mathrm{H}$-bonds, breaking the planar symmetry. The simulated absorption spectrum of 5-I (splitting: $63 \mathrm{~cm}^{-1}$ ) shows the best agreement with the experimental data $\left(41 \mathrm{~cm}^{-1}\right)$, while the calculated splittings for isomers 5-II (146 $\left.\mathrm{cm}^{-1}\right)$ and 5-III $\left(90 \mathrm{~cm}^{-1}\right)$ are much larger.

IVF. $\mathrm{NO}_{3}{ }^{-}\left(\mathrm{H}_{2} \mathrm{O}\right)_{6}$. The experimental IRMPD spectrum of $\mathrm{NO}_{3}{ }^{-}\left(\mathrm{H}_{2} \mathrm{O}\right)_{6}$ (see Figure 7) is similar to that of the $n=5$ cluster, but the splitting observed for band A $\left(29 \mathrm{~cm}^{-1}\right)$ is smaller. Band $\mathrm{B}$ is observed at $1670 \mathrm{~cm}^{-1}$ and has grown in relative intensity compared to the smaller clusters. Unresolved signal is observed below $1100 \mathrm{~cm}^{-1}$ for the first time. The lowest-energy isomer, 6-I, is similar to 5-I, with a ring of four water molecules lying above the plane of the central anion, while the two remaining waters are $\mathrm{H}$-bonded to one of the nitrate oxygen atoms, roughly lying in the plane of the central anion. In addition, both inplane water molecules accept $\mathrm{H}$-bonds from out-of-plane ones. The next highest-energy isomer, 6-II $(+4 \mathrm{~kJ} / \mathrm{mol})$, is also a variation of the 5-I structure, although for this cluster, the outof-plane ring contains five water molecules, with the sixth water roughly in the plane of the nitrate anion doubly $\mathrm{H}$-bonded to the core and accepting a H-bond from the solvent ring. Isomer 6-III $(+7 \mathrm{~kJ} / \mathrm{mol})$ again appears to be like 5 -I, but in this case, the extra water molecule forms a single hanging $\mathrm{H}$-bond with one of the four ring molecules and does not bond to the anion. Isomer 6-IV $(+18.7 \mathrm{~kJ} / \mathrm{mol})$ consists of three waters H-bonding to the nitrate core, while the remaining three waters form bridging $\mathrm{H}$-bonds to the inner water molecules. The calculated spectra of 6-I, 6-II, and 6-III give splittings of about $70 \mathrm{~cm}^{-1}$, while that for $\mathbf{6 - I V}$ is about $90 \mathrm{~cm}^{-1}$, all considerably larger than the experimental value of $29 \mathrm{~cm}^{-1}$. The calculated water bend is approximately $1640 \mathrm{~cm}^{-1}$ for all isomers, slightly lower than the experimental value.

\section{Discussion and Conclusions}

The most striking feature in the experimental IRMPD spectra is the variation of the $v_{3}$ splitting with size, which represents a sensitive probe of the hydration environment. For $n=3$, no splitting and only a minor shift compared to the $\mathrm{NO}_{3}{ }^{-} \cdot \mathrm{Ar}_{\text {data }}{ }^{7}$ is observed, signaling a hydration shell of high symmetry. In contrast, the spectra for $n=2$ and 5 show relatively large splittings $\left(>40 \mathrm{~cm}^{-1}\right)$, indicating significantly more asymmetric hydration. Interestingly, the shift observed in the condensedphase data is even larger, in the range from 60 to $70 \mathrm{~cm}^{-1} .8,9$ As it is difficult to imagine a more asymmetric hydration shell in solution than that in some of these small gas-phase clusters, this additional shift may result from the presence of counterions in solution, which are absent in our gas-phase clusters. Indeed, calculations on $\left[\mathrm{CaNO}_{3}\left(\mathrm{H}_{2} \mathrm{O}\right)_{10}\right]^{+}$find a significant increase in the $v_{3}$ splitting to $140 \mathrm{~cm}^{-1}$ in the presence of the $\mathrm{Ca}^{2+}$ counterion. ${ }^{9}$

To understand the nature of the $v_{3}$ splitting, we look at structure 1-I in more detail. The B3LYP/aug-cc-pVDZ N-O bond lengths in bare $\mathrm{NO}_{3}{ }^{-}$are $1.26 \AA$. The H-bond interaction of the water molecule with the ion leads to a reduction of the symmetry from $D_{3 h}$ to $C_{2 v}$, shortening one $(1.25 \AA)$ and lengthening two $(1.27 \AA) \mathrm{N}-\mathrm{O}$ bonds. Consequently, the originally doubly degenerate $v_{3}$ mode is split into its two components. In this particular case, these two modes are of $\mathrm{a}_{1}$ and $b_{2}$ symmetry and correspond predominantly to the in-plane displacement of the $\mathrm{N}$-atom parallel and perpendicular to the $C_{2}$ axis, respectively. In a simple picture, the frequency of the $\mathrm{a}_{1}$ mode is blue shifted because the motion of the $\mathrm{N}$-atom (parallel to the $C_{2}$ axis) is hindered by the water molecule on one side and by the somewhat closer O-atom (compared to bare $\mathrm{NO}_{3}{ }^{-}$) on the other side. The $\mathrm{b}_{2}$ mode, on the other hand, is red 
shifted because this mode predominantly involves the two longer $\mathrm{N}-\mathrm{O}$ bonds, which correspond to smaller force constants compared to bare $\mathrm{NO}_{3}{ }^{-}$.

Additional insight is gained from the evolution of the position (slight blue shift) and solvation-induced splitting of the $v_{3}$ band with the number of water molecules in the cluster. These trends are reproduced rather well by the scaled B3LYP/aug-cc-pVDZ harmonic frequencies (see Table 2), even though the extent of the splitting is overestimated, in particular, because the blueshifted part is predicted too high. On the other hand, the calculated position of the water bending modes is too low by $\sim 1.5 \%$. The calculations predict a minimum in the water bending frequency for $n=3$, in agreement with experiment. For the larger clusters, we observed a monotonic increase of this frequency, which is not reproduced by the calculations. However, the effect is small. All of these errors depend on the empirical scaling factor one uses to correct the harmonic frequencies. Different scaling factors for different bonding motifs would improve agreement with experiment, but this does not lead to any additional physical insight. The reproduction of the overall experimental trends does suggest that our calculated structural motifs are reasonable.

The differences between the calculated and experimentally observed $v_{3}$ splittings are probably the result of the complex nature of the PES describing the water-nitrate interaction. For $n=1$, the PES in the vicinity of the $C_{2 v}$ transition state (1-I) connecting the two $C_{s}$ minima $\left(\mathbf{1 - \mathbf { I } ^ { \prime } )}\right.$ is very flat, leading to pronounced deviations from the harmonic approximation, which cannot be recovered, even when anharmonic calculations based on numerical differentiation along the normal modes are performed. In other words, the flat PES leads to a significant coupling between the nitrate antisymmetric stretching and the water bending and wagging modes, which is not correctly described by our (one-dimensional) calculations and probably requires a multidimensional vibrational approach. Even though $\mathrm{NO}_{3}{ }^{-}$has a closed electronic shell, the intermediate value of 0.02 for the T1 diagnostic of the coupled cluster calculations suggests that some of the above-described discrepancies may also result from the multireference character of the electronic wave function, as one can expect when considering the possible resonance structures of the nitrate ion.

Not all calculated absorption bands are observed in the experimental spectra. This absence probably has two reasons. (1) Experimentally, the absorption of multiple photons is required to lead to photodissociation, for example, for $n=1$ ( $E_{\mathrm{diss}} \sim 60 \mathrm{~kJ} / \mathrm{mol}$ ), at least three to nine photons are needed in the spectral range from 1800 to $600 \mathrm{~cm}^{-1}$. For the smaller clusters, like $n=1$, one can assume that the absorption of a few photons in the discrete regime is required to reach the quasicontinuum regime. Thus, weak and anharmonic modes are considerably more difficult to observe in our IRMPD spectra than intense, harmonic modes. Calculations for $n=1$ indicate that the anharmonicities of the modes in between 600 and 1800 $\mathrm{cm}^{-1}$ are all similar and small, and thus, only the intensities need to be considered. (2) The absorbing cluster may change its structure and thus its absorption frequencies as it is "heated up" sequentially, one photon at a time. Consider the $n=1$ cluster, for example. The calculated absorption frequencies of 1-I, the isomer that is present before irradiation, are 1648, 1379, 1325 , and $762 \mathrm{~cm}^{-1}$. The absorption of a single photon at 706 $\mathrm{cm}^{-1}$ (water librational mode) is not sufficient to break both $\mathrm{H}$-bonds but is enough to break a single one and form isomer 1-II (+7.9 kJ/mol). Entropy will favor structure 1-II over 1-I, once it is accessible. However, isomer 1-II cannot absorb any additional photons because its absorption frequency $\left(762 \mathrm{~cm}^{-1}\right.$; see Figure 2) is now out of resonance with the irradiation wavelength by more than $50 \mathrm{~cm}^{-1}$. The water bending mode is affected similarly, but to a lesser extent; the vibrational frequency changes from 1648 (1-I) to $1633 \mathrm{~cm}^{-1}$ (1-II). The predicted change for the $\nu_{3}$ mode is smaller $(1325,1379 \rightarrow 1325$ and $1393 \mathrm{~cm}^{-1}$ ), and therefore, its intensity, which is the highest of all three modes, is affected the least by this conformational change. The mechanism described here is not specific to the nitrate ion but pertains to all microhydrated ions that contain water molecules bound in a bidentate fashion to the ion.

The present study resolves several issues regarding the structure of microhydrated nitrate ions. (1) The first three water molecules bind to the nitrate ion in a bidentate fashion, keeping the planar symmetry of the bare ion. Consequently, the groundstate structure of the $n=3$ isomer does not contain a ring of three water molecules, as predicted previously. ${ }^{17}$ (2) Starting with $n=4$, nonplanar structures with extensive water network formation are preferred. The dominating motif is not the $n=3$ structure with water molecules adding to the second hydration shell, as has been suggested, ${ }^{16}$ but rather a four-membered water ring with additional water molecules adding to the first hydration shell up to $n=6$. (3) The $n=6$ cluster has neither $D_{3 h}{ }^{20}$ nor $C_{3}{ }^{16}$ symmetry; the splitting in the $v_{3}$ band clearly supports a lower-symmetry structure, probably of $C_{1}$ symmetry. With the exception of some small structural differences, the minimumenergy structures calculated for the $n=5$ and 6 clusters are in good agreement with those located by Pathak et al., ${ }^{17}$ and the calculated IR spectra for these isomers are also in good agreement with our experimental data.

Finally, a distinct structural transition of the hydration shell is observed in between $n=3$ and 4. Below $n=4$, double $\mathrm{H}$-bond formation of water molecules to the nitrate ion is favored over single $\mathrm{H}$-bond formation and interwater $\mathrm{H}$-bonding. The lowest-energy isomers are formed by H-bonding in the plane of the nitrate anion. Breaking of the planar symmetry and the onset of extensive water-water hydrogen bonding are observed starting with $n=4$. A ring of four water molecules singly $\mathrm{H}$-bonded to each other is particularly stable and found as a structural motif in all of the larger, most stable clusters. In the larger clusters, the maximum number of $\mathrm{H}$-bonds to the ionic core is maintained, while any remaining water $\mathrm{O}-\mathrm{H}$ bonds favor an orientation which maximizes the number of interwater H-bonds. Up to $n=6$, all water molecules directly bind to the nitrate ion, that is, comprise the first hydration shell. Isomers containing free $\mathrm{O}-\mathrm{H}$ bonds and water molecules in the second hydration shell are found to lie higher in energy.

Acknowledgment. We gratefully acknowledge the support of the Stichting voor Fundamenteel Onderzoek der Materie (FOM) in providing the required beam time on FELIX and highly appreciate the skillful assistance of the FELIX staff, as well as the staff members of the Precision Mechanical Engineering Workshop (Department of Physics, Free University, Berlin) for their assistance in transporting the instrument. K.R.A. thanks M. Beyer for helpful discussions. D.M.N. and E.G. thank the Air Force Office of Scientific Research for support under Grant No. F49620-03-1-0085. E.G. thanks the National Science and Engineering Research Council of Canada (NSERC) for a post graduate scholarship.

\section{References and Notes}

(1) Finlayson-Pitts, B. J. Chem. Rev. 2003, 103, 4801.

(2) Bickmore, B. R.; Nagy, K. L.; Young, J. S.; Drexler, J. W. Environ. Sci. Technol. 2001, 35, 4481 . 
(3) Okunola, O. A.; Santacroce, P. V.; Davis, J. T. Natural and Synthetic Receptors for Nitrate Anion; 9th International Conference on Calixarene Chemistry College Park, MD, 2007.

(4) Knipping, E. M.; Lakin, M. J.; Foster, K. L.; Jungwirth, P.; Tobias, D. J.; Gerber, R. B.; Dabdub, D.; Finlayson-Pitts, B. J. Science 2000, 288, 301

(5) Markovich, G.; Pollack, S.; Giniger, R.; Cheshnovsky, O. J. Chem. Phys. 1994, 101, 9344.

(6) Cabarcos, O. M.; Weinheimer, C. J.; Lisy, J. M.; Xantheas, S. S. J. Chem. Phys. 1999, 110, 5.

(7) Relph, R. A.; Bopp, J. C.; Johnson, M. A.; Viggiano, A. A. J. Chem. Phys. 2008, 129, 064305.

(8) Waterland, M. R.; Kelley, A. M. J. Chem. Phys. 2000, 113, 6760

(9) Hudson, P. K.; Schwarz, J.; Baltrusaitis, J.; Gibson, E. R.; Grassian,

V. H. J. Phys. Chem. A 2007, 111, 544.

(10) Xu, M.; Larentzos, J. P.; Roshdy, M.; Criscenti, L. J.; Allen, H. C. Phys. Chem. Chem. Phys. 2008, 10, 4793.

(11) Salvador, P.; Curtis, J. E.; Tobias, D. J.; Jungwirth, P. Phys. Chem. Chem. Phys. 2003, 5, 3752

(12) Kido Soule, M. C.; Blower, P. G.; Richmond, G. L. J. Phys. Chem. A 2007, 111, 3349 .

(13) Dang, L. X.; Chang, T. M.; Roeselova, M.; Garrett, B. C.; Tobias, D. J. J. Chem. Phys. 2006, 124

(14) Bianco, R.; Wang, S. Z.; Hynes, J. T. J. Phys. Chem. A 2008, 112, 9467.

(15) Lee, N.; Keesee, R. G.; Castleman, A. W., Jr. J. Chem. Phys. 1980, 72,1089 .

(16) Wang, X. B.; Yang, X.; Wang, L. S.; Nicholas, J. B. J. Chem. Phys. 2002, 116, 561

(17) Pathak, A. K.; Mukherjee, T.; Maity, D. K. J. Phys. Chem. A 2008, $112,3399$.

(18) Shen, M. Z.; Xie, Y. M.; Schaefer, H. F.; Deakyne, C. A. J. Chem. Phys. 1990, 93, 3379.

(19) Waterland, M. R.; Stockwell, D.; Kelley, A. M. J. Chem. Phys. 2001, 114, 6249 .

(20) Ramesh, S. G.; Re, S. Y.; Hynes, J. T. J. Phys. Chem. A 2008, $112,3391$.

(21) Ebner, C.; Sansone, R.; Probst, M. Int. J. Quantum Chem. 1998, 70,877 .

(22) Howell, J. M.; Sapse, A. M.; Singman, E.; Synder, G. J. Chem. Phys. 1982, 86, 2345.

(23) Tongraar, A.; Tangkawanwanit, P.; Rode, B. M. J. Phys. Chem. A 2006, 110, 12918 .

(24) Zhou, J.; Santambrogio, G.; Brummer, M.; Moore, D. T.; Meijer,

G.; Neumark, D. M.; Asmis, K. R. J. Chem. Phys. 2006, 125.

(25) Bush, M. F.; Saykally, R. J.; Williams, E. R. J. Am. Chem. Soc.

2007, 129, 2220

(26) Schneider, H.; Weber, J. M. J. Chem. Phys. 2007, 127.

(27) Hammer, N. I.; Shin, J. W.; Headrick, J. M.; Diken, E. G.; Roscioli,

J. R.; Weddle, G. H.; Johnson, M. A. Science 2004, 306, 675.

(28) Asmis, K. R.; Santambrogio, G.; Zhou, J.; Garand, E.; Headrick,

J.; Goebbert, D.; Johnson, M. A.; Neumark, D. M. J. Chem. Phys. 2007, 126 .

(29) Oomens, J.; Sartakov, B. G.; Meijer, G.; von Helden, G. Int. J. Mass Spectrom. 2006, 254, 1.

(30) Oomens, J.; Tielens, A. G. G. M.; Sartakov, B.; von Helden, G.; Meijer, G. Astrophys. J. 2003, 591, 968.
(31) Asmis, K. R.; Fielicke, A.; von Helden, G.; Meijer, G. Vibrational Spectroscopy of Gas-Phase Clusters and Complexes. In The Chemical Physics of Solid Surfaces. Atomic Clusters: From Gas Phase to Deposited; Woodruff, D. P. , Ed.; Elsevier: Amsterdam, The Netherlands, 2007; Vol. $12 ;$ p 327.

(32) Goebbert, D. J.; Meijer, G.; Asmis, K. R. AIP Conference Proceedings; 2008, 1104, 22

(33) Oepts, D.; van der Meer, A. F. G.; van Amersfoort, P. W. Infrared Phys. Technol. 1995, 36, 297.

(34) Frisch, M. J.; Trucks, G. W.; Schlegel, H. B.; Scuseria, G. E.; Robb, M. A.; Cheeseman, J. R.; Montgomery, J. A., Jr.; Vreven, T.; Kudin, K. N.; Burant, J. C.; Millam, J. M.; Iyengar, S. S.; Tomasi, J.; Barone, V.; Mennucci, B.; Cossi, M.; Scalmani, G.; Rega, N.; Petersson, G. A.; Nakatsuji, H.; Hada, M.; Ehara, M.; Toyota, K.; Fukuda, R.; Hasegawa, J.; Ishida, M.; Nakajima, T.; Honda, Y.; Kitao, O.; Nakai, H.; Klene, M.; Li, X.; Knox, J. E.; Hratchian, H. P.; Cross, J. B.; Bakken, V.; Adamo, C.; Jaramillo, J.; Gomperts, R.; Stratmann, R. E.; Yazyev, O.; Austin, A. J.; Cammi, R.; Pomelli, C.; Ochterski, J. W.; Ayala, P. Y.; Morokuma, K.; Voth, G. A.; Salvador, P.; Dannenberg, J. J.; Zakrzewski, V. G.; Dapprich, S.; Daniels, A. D.; Strain, M. C.; Farkas, O.; Malick, D. K.; Rabuck, A. D.; Raghavachari, K.; Foresman, J. B.; Ortiz, J. V.; Cui, Q.; Baboul, A. G.; Clifford, S.; Cioslowski, J.; Stefanov, B. B.; Liu, G.; Liashenko, A.; Piskorz, P.; Komaromi, I.; Martin, R. L.; Fox, D. J.; Keith, T.; Al-Laham, M. A.; Peng, C. Y.; Nanayakkara, A.; Challacombe, M.; Gill, P. M. W.; Johnson, B.; Chen, W.; Wong, M. W.; Gonzalez, C.; Pople, J. A. Gaussian 03, revision C.02; Gaussian, Inc.: Wallingford, CT, 2004

(35) Frisch, M. J.; Trucks, G. W.; Schlegel, H. B.; Scusera, G. E.; Robb, M. A.; Cheeseman, J. R.; Zakrzewski, V. G.; Montgomery, J. A.; Stratmann, R. E., Jr.; Burant, J. C.; Dapprich, S.; Millam, J. M.; Daniels, A. D.; Kudin, K. N.; Strain, M. C.; Farkas, O.; Tomasi, J.; Barone, V.; Cossi, M.; Cammi, R.; Mennucci, B.; Pomelli, C.; Adamo, C.; Clifford, S.; Ochterski, J.; Petersson, G. A.; Ayala, P. Y.; Cui, Q.; Morokuma, K.; Malick, D. K.; Rabuck, A. D.; Raghavachari, K.; Foresman, J. B.; Cioslowski, J.; Ortiz, J. V.; Baboul, A. G.; Stefanov, B. B.; Liu, G.; Liashenko, A.; Piskorz, P.; Komaromi, I.; Gomperts, R.; Martin, R. L.; Fox, D. J.; Keith, T.; Al-Laham, M. A.; Peng, C. Y.; Nanayakkara, A.; Gonzalez, C.; Challacombe, M.; Gill, P. M. W.; Johnson, B.; Chen, W.; Wong, M. W.; Andres, J. L.; Gonzalez, C.; Head-Gordon, M.; Replogle, E. S.; Pople, J. A. Gaussian 98, revision A.8; Gaussian, Inc.: Pittsburgh, PA, 1998.

(36) Becke, A. D. J. Chem. Phys. 1993, 98, 5648.

(37) Lee, C.; Yang, W.; Parr, R. G. Phys. Rev. B 1988, 37, 785.

(38) Dunning, T. H. J. Chem. Phys. 1989, 90, 1007.

(39) Kendall, R. A.; Dunning, T. H., Jr.; Harrison, R. J. J. Chem. Phys. 1992, 96, 6796.

(40) El-Azhary, A. A.; Suter, H. U.; Kubelka, J. J. Phys. Chem. A 1998, 102,620 .

(41) Boys, S. F.; Bernardi, F. Mol. Phys. 1970, 19, 553.

(42) Purvis, G. D., III; Bartlett, R. J. J. Chem. Phys. 1982, 76, 1910.

(43) Raghavachari, K.; Trucks, G. W.; Pople, J. A.; Head-Gordon, M. Chem. Phys. Lett. 1989, 157, 479.

(44) Lee, T. J.; Taylor, P. R. Int. J. Quantum Chem. Symp. 1989, 23, 199.

(45) NIST Computational Chemistry Comparison and Benchmark Database, NIST Standard Reference Database Number 101; Johnson, R. D., III, Ed.; Release Sept 14, 2006; http://srdata.nist.gov/cccbdb.

JP9017103 